\section{ASPECTOS INTRODUCTORIOS AL DERECHO DEL CONSUMO*}

\author{
Juan Carlos Villalba Cuellar ${ }^{* *}$ \\ Universidad Militar Nueva Granada
}

Fecha de recepción: 14 de octubre de 2009

Fecha de aprobación: 15 de noviembre de 2009

\section{Resumen}

La protección al consumidor ha penetrado el derecho de tal forma que hoy en día se puede hablar en la mayoría de los ordenamientos jurídicos del derecho del consumo como una disciplina jurídica autónoma. En Colombia sin embargo esta tendencia no ha logrado permear las instituciones jurídicas de una manera clara y aún se conserva una legislación poco idónea para resolver las vicisitudes que la complejidad de los mercados impone a este grupo de personas denominadas los consumidores. Este artículo tiene por finalidad demostrar que el derecho del consumo es una perspectiva del derecho que tiene una fisonomía propia e involucra los aspectos más debatidos del derecho privado y del derecho de la empresa en la actualidad. Para tal fin se abordará primero la

\footnotetext{
Este artículo pertenece a la investigación denominada "El sistema de protección al consumidor en Colombia. Una perspectiva desde el derecho comparado", correspondiente al grupo de "Derecho Privado", línea de investigación sobre "Derecho Económico y de los Negocios" que se adelanta en el Centro de Investigaciones Jurídicas, Políticas y Sociales (C.I.D.E.R.) de la Facultad d e Derecho de la Universidad Militar Nueva Granada.

** Abogado, docente e investigador, miembro de la línea en Derecho Económico y de los Negocios, grupo en Derecho Privado del Centro de Investigaciones de la Facultad de Derecho de la Universidad Militar Nueva Granada. Director de Postgrados de la Facultad de Derecho de la Universidad Militar Nueva Granada. Magíster LLM en Derecho francés, europeo e internacional de negocios de la Universidad Panthéon-Assas Paris II y el Instituto de Derecho Comparado de Paris (Francia). Especialista en docencia universitaria. juan. villalba@unimilitar.edu.co
}

evolución de la protección a los consumidores en el derecho comparado, para en un segundo lugar caracterizarlo y finalmente delimitar el derecho del consumo de tal forma que se sepa cuál es su contexto y real alcance.

\section{Palabras clave}

Derecho del consumo, protección al consumidor.

\section{INTRODUCTORY ASPECTS OF CONSUMER LAW}

\begin{abstract}
Consumer protection law has penetrated so that today we can speak in most legal systems of consumer law as an autonomous legal discipline. In Colombia, however, this trend has failed to permeate the legal institutions of a clear and still retains some appropriate legislation to resolve the uncertainties that the complexity of the market requires this group of people called consumers. This article aims to show that consumer law is a legal perspective, which has its own character and involves the most debated aspects of private law and business law today. To this end we first address the evolution of consumer protection in comparative law, to characterize in second place and finally define the consumer law so that we know what is real context and scope.
\end{abstract}

\section{Key words}

Consumer law, consumer protection.

\section{INTRODUCCIÓN}

En el contexto colombiano hacer referencia al derecho del consumo todavía resulta algo extraño, la doctrina al respecto resulta escasa, algunos autores que se ocupan del derecho de la competencia hacen mención del tema dejándolo como secundario, los manuales de obligaciones y contratos lo ignoran, la jurisprudencia brilla por su ausencia. Existe doctrina de la Superintendencia de Industria y Comercio, 
entidad encargada de vigilar la protección al consumidor, consistente en conceptos emitidos durante los últimos años. En igual forma las resoluciones emitidas por esta entidad ayudan a clarificar algunos aspectos de la aplicación de la normatividad vigente en Colombia sobre el tema. En este orden de ideas hay algo que llama la atención, mientras en el derecho comparado el derecho del consumo ha tenido un papel protagónico y unos avances importantes, por ejemplo en el contexto del derecho comunitario europeo, en el ordenamiento jurídico colombiano y en la academia parece que el tema no genera mayor interés. Sin embargo en foros de discusión sobre derecho privado, sobre todo, algunos temas que son propios del derecho del consumo ya se comienzan a debatir, tales como la responsabilidad por productos defectuosos, la protección del contratante débil, entre otros. La pregunta que debe hacerse entonces es: ¿existe en Colombia un verdadero derecho del consumo?

Frente a este fenómeno podemos hacer varias conjeturas, una podría consistir en que en este país, a diferencia del resto del mundo, los consumidores no tienen problemas, por lo tanto no existe una necesidad real de protegerlos. Esta proposición no resiste mayor análisis y debe ser descartada. En segundo lugar, la legislación existente en Colombia al respecto es suficiente y se encarga de proteger debidamente a los consumidores, por lo tanto no es necesario promover nuevas normas, y frente a temas como la regulación de contratos con consumidores, la protección de la formación del consentimiento en contratos de consumo, la publicidad desleal, las cláusulas abusivas, todo está dicho o más bien, no es necesario decir nada. Ante esta segunda hipótesis se considera que si bien es cierto existe legislación que protege a los consumidores en el ordenamiento jurídico colombiano, no es suficiente y debe ser mejorada, ya que en los últimos años el mercado interno colombiano ha sufrido grandes cambios, por ejemplo, celebración de tratados de libre comercio, concentración de los mercados, ingreso de grandes multinacionales al país, etc. En tercer lugar, si bien se reconoce la importancia de algunos temas propuestos, no se acepta que el tema de la protección al consumidor merezca ser categorizada como una especie de derecho, el derecho del consumo, se trata más bien de un aspecto propio de un estatuto y algunas normas dispersas, un derecho sin cuerpo propio, una especie de derecho de tercera, insignificante, para ciudadanos de tercera. Con relación a esta hipótesis se debe decir que sí se trata de un nuevo derecho, el cual tiene justificación de raigambre constitucional y que las normas de protección al consumidor no son normas de tercera categoría, innecesarias, sino que se trata de normas importantes que han logrado penetrar muchas ramas del derecho.

Teniendo en cuenta el panorama anterior, este artículo tiene como finalidad hacer un esquema de lo que es el derecho del consumo, explicando su evolución, su razón de ser, sus características, su campo de acción, de tal forma que no queden dudas acerca de la consideración de este derecho como un derecho importante, moderno, autónomo, necesario en las relaciones jurídicas y económicas del mundo actual. Todo esto tratando de combatir la aparente displicencia y papel secundario con que se le ha tomado en el contexto colombiano.

Plan: Se abordará primero la evolución del derecho del consumo moderno, sin remitirnos a antecedentes lejanos, que sin duda existen; para darle lugar a la definición y caracterización; finalmente se hará una delimitación del ámbito de aplicación del mismo.

\section{HISTORIA Y EVOLUCIÓN}

El derecho del consumo es una categoría jurídica reciente que hizo su aparición como consecuencia de la necesidad de regular las 
relaciones las relaciones jurídicas de los ciudadanos cuando estos actúan en el mercado bajo ciertas circunstancias. Se habla hoy en día de los consumidores como un grupo específico de personas que son objeto de protección por parte del legislador. El consumidor como sujeto jurídico hizo su aparición en la medida en que los países occidentales iban alcanzado grados avanzados de capitalismo, pues hasta entonces el destinatario de productos o servicios era sólo el eslabón final del sistema, era digno de atención únicamente como "metro" de valoración del comportamiento del homo oeconomicus, como espectador externo de ciertas acciones con una participación únicamente final ${ }^{1}$.

Esa necesidad de protección se hizo patente en el siglo pasado en el cual en la sociedad estadounidense se conformaron asociaciones con la finalidad de proteger los intereses de los consumidores. Algunos hombres políticos asumieron las banderas de la protección a los consumidores y es recordado en el contexto de los Estados Unidos el discurso en que el 15 de marzo de 1962 pronunciara el presidente Kennedy en el cual afirmaba que todos somos consumidores y defendía el derecho que tienen los consumidores a ser informados, el derecho a la seguridad, el derecho a escoger y ser oidos. ${ }^{2}$ En efecto, fue en el ámbito de los Estados Unidos que la normatividad de protección al consumidor se desarrolló, estos movimientos fueron denominados consumeristas. Tres movimientos consumeristas se distinguieron en los Estados Unidos principalmente en las décadas de los años 1900, 1930 y $1960^{3}$. El primero se

1 ALPA, Guido. El derecho de los consumidores y el "Código del Consumo" en la experiencia italiana, en revista de derecho privado No. II-2006, p.7, Universidad Externado de Colombia.

2 Consumer protection in the United States

3 En la década de 1890 se presentaron varios proyectos de ley por parte de abogados defensores de los consumidores que denunciaban el uso de aditivos y preservantes peligrosos para el hombre en la industria alimenticia, los cuales fueron derrotados. dio en la administración del presidente Teodoro Roosevelt de 1901 a 1909 en la cual se aprobó el Pure Food an Drug Act de 1906, como consecuencia de graves denuncias efectuadas por periodistas, escándalos en materia de farmaceuticos $^{4}$ y los escritos polémicos de Upton Sinclair quien en 1906 publicó The Jungle, un texto en el que este socialista denunciaba graves irregularidades en plantas de procesamiento y empaque de alimentos en Chicago.Esta ley creó un sistema de inspecciones oficiales en plantas procesadoras de alimentos. En 1914 fue creada la Federal Trade Commission, entidad encargada de regular la competencia en el mercado y velar por mantener el mercado libre de engaños. En la década de 1920 la consolidación del automóvil como medio de transporte y el fortalecimiento de los medios publicitarios que promovían un estilo de vida americano aumentaron el consumismo. Entre 1920 y 1930 se produjeron envenenamientos y desfiguraciones ocasionadas por cosméticos y muertes producidas por medicamentos. E1 segundo movimiento de protesta de los consumidores se dio a mediados de los años treinta a causa del aumento excesivo de los precios en medio de la crisis económica mundial denominada "la gran depresión", la huelga de las amas de casa en Detroit y el escándalo de la sulfanilimida 5 . Como resultado, el gobierno de Franklin D. Roosvelt en 1938 aprobó una ley que fortalecía el Pure Food an Drug Act y le daba nuevos poderes a la Federal Trade Commission para combatir la publicidad engañosa ${ }^{6}$. Rexford g Tugwell, asistente de la secretaría de agricultura del gobierno del presidente Roosevelt, inició de campañas de denuncia de sustancias peligrosas y promovió el cambio de legislación en materia de alimentos,

4 OVALLE FAVELA, Jorge. Los derechos del consumidor, p.1, Cámara de Diputados, Universidad Nacional Autónoma de México, en google libros.com.

$5 \quad$ Ibid. p. 4.

6 Consumer protection in the United States. 
medicamentos y cosméticos. ${ }^{7}$ Después de la segunda guerra mundial los Estados Unidos vivieron una época de gran prosperidad, los ciudadanos norteamericanos consumían en exceso, carros, electrodomésticos, entretenimiento, etc. El tercer movimiento se dio en la mitad de la década de los años sesenta gracias al impulso que le dio al movimiento el presidente Kennedy en el referido discurso y la promulgación de la carta de derechos de los consumidores. En igual forma la labor de activistas como el abogado Ralph Nader, quien en 1965 publicó el libro Unsafe at Any Speed en el cual revelaba graves irregularidades en la industria automotriz, la cual se preocupaba más por el diseño y la comodidad de los automóviles que por la seguridad. La bióloga Rachel Carson publicó en los años sesenta el libro Primavera Silenciosa, en el cual documentaba la utilización de algunos plaguicidas que contaminaban la cadena alimentaria y generaban enfermedades en los seres humanos, lo cual influyó en parte en la creación en 1970 de la Agencia para la Protección Ambiental.

La sociedad estadounidense se hizo consciente de la necesidad de promover la protección al consumidor en la medida que el país se iba consolidando como una potencia industrial, que la capacidad adquisitiva de los ciudadanos era más alta y que grandes industrias de ese país se posicionaron en los mercados mundiales. En el país modelo de capitalismo la necesidad de hacer contrapeso al ímpetu de la sociedad de consumo dio lugar a la aparición de legislación y entidades protectoras de los intereses de los consumidores.

En la década de los años sesenta en el contexto de la Comunidad Económica Europea (hoy Unión Europea), se comenzó a legislar en la materia de protección al consumidor. E1

DURAND CARRION, Julio. Tratado de derecho del consumidor en el Perú, p. 40, Universidad San Martin de Porres, $1^{\text {a }}$ edición, Lima, 2007.
Tratado de Roma de 1957 no hace referencia ala protección al consumidor, sin embargo no se puede desconocer que este es un actor esencial del mercado, por lo cual para la consecución de las cuatro libertades fundamentales en que se basa hoy en día el mercado común este debe ser protegido. El texto original del tratado no se ocupaba directamente de este tema, para esa época el desequilibrio entre productores y consumidores no era claramente percibido ${ }^{8}$. En el año de 1972 en un encuentro de jefes de Estado y de gobierno reunidos en Paris, se determinó que la Comunidad debería buscar ir más allá de la expansión económica y propender por mejorar las condiciones de vida y de trabajo de sus ciudadanos, para lo cual deberían adoptarse nuevas políticas en materia de mejoramiento de las medidas adoptadas para proteger a los consumidores. En el año 1975 se presentó un "Programa preliminar de la CEE para una política de protección y de información a los consumidores", que se refería a cinco derechos fundamentales de los consumidores: el derecho a la protección de la salud y la seguridad, el derecho a la protección de sus intereses económicos, el derecho a la reparación de los daños, el derecho a la información y la educación y el derecho a ser oído. Este programa fue seguido otro en 1981, y el de 1986 para "un nuevo impulso de una política de protección y promoción de los consumidores" 9 . En general puede afirmarse que la protección al consumidor en el contexto comunitario europeo tiene dos grandes etapas, la época anterior al tratado de Maastrich que sirvió gestación del derecho del consumo comunitario en aras de lograr la consolidación del mercado interior; después del tratado de Maastrich la Unión Europea asume una política clara de protección al consumidor y define la necesidad de unificar y armonizar las normatividades nacionales sobre la materia

8 CALAIS AULOY, Jean, Droit de la Consommation, p. 40, 7e édition, Dalloz, Paris, 2006.

$9 \quad$ Ibid. P. 9, 40 y 41. 
como un punto clave para el desarrollo del mercado interior ${ }^{10}$.

En el Tratado de Maastrich el título XI denominado "Protección de los consumidores" se refirió por primera vez a estos y en 1997 el Tratado de Ámsterdam modificaría este artículo para convertirse en el artículo 153 del actual Tratado CE, el cual dice:

"Para promover los intereses de los consumidores y garantizarles un alto nivel de protección, la Comunidad contribuirá a proteger la salud, la seguridad y los intereses económicos de los consumidores, así como a promover su derecho a la información, a la educación y a organizarse para salvaguardar sus intereses.

2. Al definirse y ejecutarse otras políticas y acciones comunitarias se tendrán en cuenta las exigencias de la protección de los consumidores.

3. La Comunidad contribuirá a que se alcancen los objetivos a que se refiere el apartado 1 mediante:

a) medidas que adopte en virtud del artículo 95 en el marco de la realización del mercado interior;

b) medidas que apoyen, complementen y supervisen la política llevada a cabo por los Estados miembros.

4. El Consejo, con arreglo al procedimiento previsto en el artículo 251 y previa consulta al Comité

Económico y Social, adoptará las medidas mencionadas en la letra b) del apartado 3.

5. Las medidas que se adopten en virtud del apartado 4 no obstarán para que cada uno de los Estados miembros mantenga y adopte medidas de mayor protección. Dichas medi-

10 POILLOT, Elise. Droit Européen de la Consommation et uniformisation du droit des contrats, p. 43- 44, LGDJ, Paris, 2006. das deberán ser compatibles con el presente Tratado".

El artículo 30 del Tratado se refiere a la protección de la salud y la vida de las personas, con lo cual sienta uno de los pilares fundamentales del derecho del consumo, el derecho a la seguridad. Por otro lado, los artículos 33, 34 y 82 se refieren en materia de política común a "asegurar al consumidor suministros a precios razonables", a la exclusión de "toda discriminación entre productores y consumidores de la comunidad" y a la "limitación de la producción, los y el desarrollo técnico en perjuicio de los consumidores".

En igual medida la carta de Derechos Fundamentales de la Unión Europea consagró como principio "asegurar un nivel elevado de protección a los consumidores". La Corte de Justicia de las Comunidades Europeas ha jugado un rol muy importante en la aplicación e interpretación de la normatividad europea en materia de protección al consumidor.

Después de haberse aceptado la protección a los consumidores como un principio necesario para el desarrollo de la integración económica y social, el derecho europeo del consumo se fue construyendo a partir de directivas que contribuyeron a la armonización de este derecho en los diferentes Estados de la Unión Europea. En diferentes ámbitos se fueron creando directrices comunes, tales como la protección de la salud y la seguridad, la protección de intereses económicos de los consumidores (publicidad engañosa, venta a distancia, ventas a crédito, cláusulas abusivas, prácticas comerciales agresivas y desleales, entre otros), la reparación de daños sufridos por los consumidores, la información dada a los consumidores, principalmente.

Paralelamente encontramos que los Estados miembros fueron adecuando sus normatividades internas a las exigencias de las Directivas Europeas, consolidándose un nivel de 
protección al consumidor armonizado legalmente, cada cual a su manera, por ejemplo, algunos países como Francia e Italia crearon sus propios códigos del consumo, en otros como España se mantiene la ley de defensa del consumidor LGDC de manera independiente, y en Alemania en la última reforma al BGB de 2003 se integró esta normatividad en el régimen general de las obligaciones y los contratos.

En Colombia la Ley 73 de 1981 facultó Presidente de la República para expedir normas en materia de responsabilidad de los productores por la idoneidad de los bienes y servicios que se ofrecen en el mercado, por la información ofrecida a los consumidores y la prestación de servicios que requieran el depósito de los bienes de propiedad de los usuarios, entre otros. A virtud de esta ley el gobierno expidió el decreto 3466 de 1982, conocido como estatuto del consumidor, en el cual se desarrollan las materias citadas por la ley $31 \mathrm{El}$ mencionado decreto, denominado por algunos "estatuto del consumidor" es una norma que fue revolucionaria en su momento de expedición, por novedosa y vanguardista, teniendo en cuenta que en muy pocos ordenamientos jurídicos existían normas sobre la materia. Sin embargo, más de dos décadas después se pasó de contar con una legislación de avanzada en el tema a un rezago normativo en palpable con respecto a muchos otros países. La norma permanece intacta y cada cierto tiempo se presenta una propuesta de reforma a la legislación en la materia que rápidamente se archiva en el Congreso de la República. Mientras este derecho ha logrado los más importantes avances en los últimos treinta años en el derecho comparado, la legislación local ha permanecido en estado de letargo en este periodo, a pesar de que otras normas regulan aspectos de la materia, tales como la ley 142 de 1994 en materia de servicios públicos domiciliarios y la recién expedida reforma financiera.

\section{EL DERECHO DEL CONSUMO}

\subsection{Definición}

El derecho del consumo es aquel que regula los intereses de los consumidores y las relaciones de consumo en genera ${ }^{11}$. Aunque no es común definir el derecho del consumo, esta definición se considera acertada pues la finalidad es la regulación de todas las situaciones jurídicas que pongan en juego intereses de los consumidores $^{12}$. En igual forma el derecho del consumo hace su aparición cuando en cualquier relación jurídica obligacional de naturaleza contractual se encuentre en uno de los extremos un consumidor. Esta relación jurídica ha sido denominada por la doctrina la relación de consumo, constituida por un consumidor y un productor (o profesional). Sin embargo el derecho del consumo desborda el ámbito de las meras relaciones contractuales, señala Farina: "el derecho de los consumidores vas más allá de la adquisición de bienes y servicios ofrecidos por las empresas, pues incluye el interés de obtener respuesta a otras necesidades cuya satisfacción no ofrece el mercado y que, sin embargo, también son indispensables para asegurar la calidad de vida. Piénsese en la necesidad de una eficiente prestación de servicios públicos, en la defensa del medio ambiente, en la educación e información necesarias no sólo para contratar en el mercado, sino para conseguir las mejores condiciones de vida.

11 PÉREZ BUSTAMANTE, Laura. Derechos del consumidor, p.2, Editorial Astrea, Buenos Aires 2004

12 Para CALAIS- Auloy el derecho del consumo está constituido por reglas que responde a dos criterios fundamentales: a) su aplicación está reservada a relaciones entre profesionales y consumidores b) su finalidad es proteger a los consumidores. Aunque para este autor la concepción debe ser más extensa pues en algunos casos el derecho del consumo cobija aspectos que se aplican de manera general, tales como la responsabilidad por productos defectuosos y la publicidad engañosa. Calais Auloy Jean, Droit de la consommation, p. 18, Dalloz, Paris, 2006. 
Esto excede el campo de las contrataciones mercantiles" 13 .

Se ha tratado de justificar de manera general la existencia del derecho del consumo como un derecho proteccionista de una persona en estado de debilidad, el consumidor, frente a otra que se encuentra en posición de dominio frente a este, el productor, creándose una relación de aparente antagonismo, entre buenos y malos, 1o que ha generado malestar en ciertos doctrinantes $^{14}$. En lo absoluto, esta concepción debe ser atemperada, el derecho del consumo no busca estigmatizar a alguna de las partes de la relación jurídica, sino más bien corregir los desequilibrios que se presentan eventualmente en ésta, dándole al consumidor una herramienta para lograr la protección de los derechos que tiene en calidad de tal. El consumidor no necesariamente está en posición de debilidad ni debe ser considerado un ser inferior, por el contrario, la tendencia en el derecho moderno es tomarlo como una persona medianamente informada y perspicaz ${ }^{15}$. Sin embargo, la mentada asimetría

13 FARINA, Juan M. Contratos comerciales modernos, p. 322, Editorial Astrea, Buenos Aires, 2005.

14 RUBIO ESCOBAR manifiesta que "cuando la concepción de los temas de consumidor se enfoca enla expedición de estatutos o normas que buscan generar limitaciones, restricciones, obligaciones, y sanciones, tal concepción parte de una premisa básica, y es que existen una personas débiles (consumidores) que deben ser defendidas de otras fuertes (productores y vendedores): Esta visión se estructura en una contraposición de fuerzas disparejas, que de alguna forma debe ser nivelada mediante la intervención de un sujeto poderoso (Estado) que no solo nivele las cargas, sino que además castigue a 1s "malos". Bajo estos parámetros, las relaciones que se generan son de contienda entre buenos y malos, o débiles, fuertes y más fuertes." Rubio Escobar Jairo, Derecho de los Mercados, p. 472, Legis, Bogotá, 2007.

15 Al respecto ver, GONZÁLEZ VAQUÉ, Luis, Las nociones de consumidor medio y miembro de un grupo particular de consumidores en el Reglamento No. 1924/2006, en gaceta jurídica de la Unión Europea y de la competencia, No. 247, 9-19. (2007). Ver igualmente las sentencias Gut Springenheide, Darbo C- 465/98 TJCE y sentencias TJCE 126-91, 315-92, 456-93, en las relaciones de consumo no es una ficción, la regla general es que el productor tiene a su disposición una serie de herramientas que le permiten adquirir una ventaja frente al consumidor, tales como la publicidad, las técnicas de marketing y de ventas, la posibilidad de establecer las reglas generales de contratación, etc. E1 productor detenta la información y los medios de divulgación de ésta, lo cual le da un poder frente al consumidor, el cual en la mayoría de los casos queda sujeto a información brindada como factor para la manifestación del consentimiento en las relaciones contractuales con el productor o distribuidor. Al respecto señala Vega Mere que "la información permite una elección suficientemente conciente y racional por parte de los consumidores. El tema se vincula con la asimetría informativa que existe en los mercados y que tiende a ser combatida debido a la imperfección de los mercados para ofrecer todos los datos esperables del mismo" ${ }^{16}$. Citando a Onado, este doctrinante afirma que existe asimetría informativa cuando los agentes económicos (consumidores y proveedores) disponen de fragmentos informativos, es decir, datos no completos y hasta distintos. Esta asimetría puede conducir a la parálisis de los cambios o a la actuación de cambios en circunstancias no óptimas para uno o más contratantes ${ }^{17}$.

A través del funcionamiento del libre mercado no se logra un nivel efectivo de protección al consumidor, esto por sí solo no es no es suficiente. Según la doctrina "la economía de libre mercado suponía, entre otras cosas, que la demanda del consumidor orienta la producción, y que la libre competencia conducía a una mayor disponibilidad y calidad de bienes ofrecidos en el mercado, paralelamente a la

470-93, 239-90, 132-03, 169-99, 212-03, 358-01, 99-01, 104-00.

16 VEGA MERE, Yuri. Contratos de Consumo, p. 95, 96. Editorial Grijley, Lima, 2001.

$17 \quad$ Ibid., p. 95, 96. 
disminución de su precio y al aumento de la calidad de vida; no siendo necesario, por lo tanto, protegerlo más allá de ciertas reglas concretas, destinadas a reprimir prácticas ilícitas... Sin embargo la realidad ha demostrado lo contrario; la expansión industrial coincidió con un aumento muy importante del poder económico de las empresas, con la sofisticación de los productos y con la cada vez más poderosa influencia de la publicidad que induce al consumo, todo lo cual ha terminado por instaurar un profundo desequilibrio entre las empresas y los consumidores"18. Por lo tanto debe erradicarse la idea de que las normas sobre competencia son suficientes para proteger al consumidor, en realidad cumplen un papel importante en este propósito, pero no pueden ser el único instrumento dedicado a tal fin.

El derecho del consumo no pierde su neutralidad ni su eficiencia por el hecho de ser proteccionista del consumidor, porque este corrige situaciones anómalas excepcionales que perjudican a este último. Por esta misma razón los estatutos de protección al consumidor no son Códigos Civiles o de Códigos de Comercio paralelos, ya que sólo regulan algunas materias o situaciones en que se considera que eventualmente el consumidor puede verse en desventaja, por ejemplo, el deber de información en el etiquetaje de productos, la publicidad engañosa.

En este orden de ideas, el derecho del consumo se erige como un derecho autónomo, un microsistema de reglas y principios, que parece haber adquirido la mayoría de edad al comenzar a influir reformas en los más importantes códigos civiles del mundo como el BGB alemán ${ }^{19}$.

18 WEINGARTEN, Celia. Derecho del Consumidor, p. 56,57, Editorial Universidad, Buenos Aires, 2007.

19 LORENZETTI, Ricardo Luis. Tratado de los Contratos, parte general, p 80, 81, Rubinzal Culzoni editores, Buenos Aires, 2004.

\subsection{Características del derecho del consumo}

Con fundamento en la cantidad de materias que el derecho del consumo regula y el desarrollo legislativo que ha tenido en el mundo podemos acercarnos a delinear lo que caracteriza al derecho del consumo.

\subsubsection{Es un derecho transversal}

El derecho del consumo no es una nueva rama del derecho, es una disciplina jurídica nueva que no pertenece completamente al derecho privado o al derecho público, porque el derecho del consumo se ubica transversalmente en el ordenamiento jurídico. Debe tenerse en cuenta que el derecho del consumo no se reduce al estatuto de protección al consumidor, sino que existe una extensa normatividad en la cual se encuentran disposiciones sobre el tema, tales como el estatuto orgánico del sistema financiero, la ley de servicios públicos domiciliarios, regulación en materia de seguros, transporte, salud, entre otros. Al respecto Rivero afirma que: "En efecto, desde la Constitución hasta los decretos, de las sentencias al contrato, de las normas escritas a las no escritas, todo el ordenamiento jurídico tiene que ver con el derecho del consumidor. Precisamente por ello, por cortar transversalmente todo el ordenamiento jurídico, es que el derecho del consumidor no puede ser limitado o encasillado en un sistema determinado, sea este el derecho civil, constitucional, penal, administrativo, etc." ${ }^{20}$.

\subsubsection{Es un derecho pluridisciplinario}

Esta característica está intrínsecamente relacionada con la anterior, ya que el derecho del consumo no se inscribe dentro de la clasificación de las disciplinas jurídicas tradicionales: derecho penal, derecho civil,

20 RIVERO SÁNCHEZ, Juan Marcos. Quo vadis- derecho del consumidor, p. 33, biblioteca jurídica Diké, Medellín, 1997. 
derecho administrativo, etc. El derecho del consumo hace parte de una nueva categoría de disciplinas jurídicas que atraviesan las demás, tales como el derecho de la competencia, el derecho del medio ambiente, el derecho de la empresa, entre otras. Durand Carrión afirma sobre este tema: "El hecho de que los intereses de los consumidores ofrezcan una diversa naturaleza en cada uno de los momentos del proceso económico (producción, transporte, comercialización, oferta, venta y postventa y consumición o utilización) explica el carácter pluridisciplinario de la tutela jurídica del consumidor, por cuanto que la naturaleza de las normas jurídicas protectoras de los intereses de los consumidores varía en cada uno de esos momentos del proceso económico (normas civiles, mercantiles, administrativas, económicas, penales, de policía, de mercado, etc.)"21.

El derecho del consumo tiene que ver con las siguientes ramas del derecho:

- El derecho civil, porque las relaciones de consumo dan lugar en la mayoría de los casos a contratos de derecho privado ${ }^{22}$, que implican la aplicación de aspectos como los vicios del consentimiento, los vicios ocultos de la cosa vendida, la responsabilidad civil. El derecho del consumo se integra en el derecho civil al reemplazar algunas veces las reglas del derecho común para darle paso a reglas de carácter especial, por ejemplo en materia de relaciones contractuales el derecho de retracto reemplaza las normas generales del contrato del Código Civil en lo atinente a la terminación del contrato.

- El derecho comercial. Algunas disposiciones del derecho del consumo imponen obligaciones específicas a los comerciantes, tales como el deber de información en materia de fijación de precios, la obligatoriedad de la

21 DURAND CARRIÓN. Op. cit. p 53.

22 CALAIS AULOY. Op cit. p.19. oferta a persona indeterminada (en el caso de mercaderías en vitrinas y no en folletos o circulares como absurdamente lo establece el Código de Comercio colombiano), en materia de publicidad y etiquetaje. En igual forma el deber de garantía sobre los productos vendidos. Debe observarse también que la relación de consumo está conformada por un productor y un consumidor, siendo el primero en todos los casos un comerciante, por lo cual se puede afirmar que los contratos de consumo son contratos que tiene vocación a que la norma comercial se aplique de manera general, aunque por ser un derecho especial prime la aplicación de la norma de consumo. Por lo tanto en materia de contratos comerciales no debe perderse de vista que el derecho del consumo muchas veces estará presente. El derecho comercial ha sido tradicionalmente es el derecho de los comerciantes y se focaliza en los actos de comercio, sin embargo, en algunos aspectos de su interés se relaciona actualmente con el derecho del consumo.

- El derecho de la competencia es una rama del derecho económico que guarda estrecha relación con el derecho del consumo, el cual al regular los comportamientos de los agentes del mercado tiene en cuenta al consumidor por tratarse del eslabón final de la cadena productiva, un agente económico que demanda bienes y servicios que se ofrecen en el mercado. En ciertos países europeos existe una tendencia a que las reglas sobre competencia sean complementadas con un nivel de protección alto al consumidor y en algunos casos los análisis de comportamientos anticoncurrenciales se han centrado en la protección al consumidor ${ }^{23}$. La relación entre la promoción de la competencia, la propiedad industrial y la protección del consumidor es

23 NIHOUL, Paul. Introducción al Derecho de la competencia, p. 22,Universidad Externado de Colombia, Bogotá, 2005.

Bogotá, D.C. Colombia - Volumen XII - No. 24 - Julio - Diciembre 2009 - ISSN 0121-182X 
resaltada por Rubio Escobar quien establece un símil con la Santísima Trinidad, tres disciplinas distintas con un solo objetivo común: el bienestar del consumidor. ${ }^{24}$ Afirma igualmente este autor: "En efecto, sean cuales sean las finalidades que persiga el derecho de la competencia, lo cierto es que el objetivo principal y primario del mismo es el bienestar de los consumidores. La competencia lleva a que las empresas sean eficientes, y esas eficiencias hacen que a los consumidores se les garantice la calidad y el precio de los bienes y servicios en términos crecientemente satisfactorios... Si no existiera competencia, los consumidores se verían abocados a adquirir el único bien que se les ofrezca, sin importar calidad y precio, pues no habría otro en el mercado" 25 .

- El derecho administrativo. En la mayoría de los casos y en el caso colombiano existen autoridades encargadas de velar por el cumplimiento de las normas de protección al consumidor. En Colombia la Superintendencia de Industria y Comercio tiene encargada esta labor, la cual ejerce a través de la delegatura para la protección al consumidor. Esta competencia implica que a través de procedimientos administrativos se investiguen las infracciones a estas normas y se impongan sanciones administrativas. Además en el ejercicio de la protección al consumidor se verán siempre involucradas entidades de naturaleza pública o que desarrollan actividades de interés colectivo, por ejemplo, empresas prestadoras de servicios públicos, entidades financieras, hospitales, empresas de transporte, entre otras.

\subsubsection{Es derecho económico}

El derecho del consumo hace parte de lo que se conoce hoy en día como derecho económico,

\footnotetext{
24 RUBIO ESCOBAR, Jairo. Op. cit. p. 6.

25 Ibid. p. 8.
}

el cual cobija el conjunto de normas jurídicas de contenido económico que tienen como finalidad regular la economía, para alcanzar un punto de equilibrio que la haga lo más eficiente posible ${ }^{26}$. Según Marquez "en materia económica la protección al consumidor se requiere por la asimetría de la información que puede haber antes de la realización del negocio, y en el daño al mercado proveniente de los costos de transacción tan altos a los que deberían someterse los consumidores, entre ellos la obtención de la información principalmente. En un mercado de competencia perfecta, la información de los agentes es completa, es decir, todos los agentes tienen acceso a toda la información del mercado. Esta información completa se transmite a través del precio de los bienes y de los servicios. Si el mercado no es de competencia perfecta, y especialmente cuando tal causa está dada por la asimetría de la información debido a la información incompleta, se genera una posición de dominio de las que es fácil abusar por parte del conocedor de la información. E1 Estado debe corregir esta falla del mercado buscando eliminar las fortalezas adquiridas por los tenedores de la información cuando tal situación perjudique al mercado" 27 .

\subsubsection{Es un derecho especial}

Frente a las ramas del derecho tradicionales como el derecho civil, el derecho comercial, el derecho administrativo, entre otros, el derecho del consumo es de carácter especial y por lo tanto su aplicación es preferente frente a normas de carácter general.

\subsubsection{Es un derecho proteccionista}

El derecho del consumo rompe con el esquema tradicional que concibe la igualdad de los

26 MÁRQUEZ ROBLEDO, Felipe. Apuntes de derecho económico y de la competencia, segunda edición, $\mathrm{p}$. 15, Universidad Javeriana, Bogotá, 2007.

$27 \quad$ Ibid., p. 209. 
individuos en las relaciones jurídicas. En materia contractual las relaciones de consumo son consideradas asimétricas porque el consumidor es la parte débil del vínculo obligacional, ya sea contractual o extracontractual. En algunos casos se considera que el productor o prestador del servicio se encuentra en posición de dominio contractual frente a su cocontratante ${ }^{28}$. El postulado de la autonomía de la voluntad privada sufre una derogación en esta materia, porque en materia de contratos de consumo el legislador interviene a favor del consumidor, a pesar de que este se hubiere obligado en este $u$ otro sentido, de modo tal que quien dice contractual no dice justo. En este sentido Mosset Iturraspe señala: "La aparición del "Derecho de La Consumición". Fue un imperativo de la observación acerca del tráfico entre empresario y consumidor. En esta relación los postulados de libertad y autonomía contractual quedan muchas veces afectados. La fraternidad se desdibuja, la igualdad, en situaciones plurales, desaparece. Tal y como observa Reich, en la doctrina alemana, "los principios civilísticos tradicionales no son suficientes y deben, como en el Derecho del Trabajo, buscarse otras soluciones para relativizar el desnivel de poder entre el empresario y el consumidor" ${ }^{29}$. Puede observarse que la mayoría de tratadistas justifica la existencia del derecho del consumo en el interés proteccionista sobre los consumidores dadas las condiciones de los mercados en la actualidad. Marco Velilla en lo atinente a la razón de ser del derecho del consumo señala que "Aunque el equilibrio contractual ha sido

$28 \quad$ La ley de servicios públicos domiciliarios colombiana en su artículo 14.13 define la posición dominante como: La que tiene una empresa de servicios públicos respecto a sus usuarios; y la que tiene una empresa, respecto al mercado de sus servicios y de los sustitutos próximos de éste, cuando sirve al $25 \%$ o más de los usuarios que conforman el mercado.

29 MOSSET ITURRASPE, Jorge. Lorenzetti Ricardo Luis, Defensa del Consumidor, p. 22, Rubinzal Culzoni Editores, Buenos Aires, 1993. una preocupación constante en el derecho de los contratos, la profunda transformación en las condiciones de la producción y de la distribución ha generalizado la celebración de contratos en los cuales el consumidor tiene que aceptar o rechazar en bloque las condiciones del contrato, sin tener la posibilidad de discutirlas con quien ha preestablecido el contrato (contratos de adhesión), quien puede incluso llegar a abusar de su poder, fabricando el contrato a su medida o incluyendo sólo las cláusulas que le sean más favorables." ${ }^{30} \mathrm{Se}$ puede afirmar que el carácter proteccionista del derecho del consumo ha permeado necesariamente el derecho de los contratos, por lo cual se habla de una nueva categoría de contratos, los contratos de consumo.

\subsubsection{Sus normas son de orden público}

Las normas del derecho del consumo son por regla general de orden público, de tal forma que no pueden ser derogadas por la voluntad de los particulares. Esta característica encuentra su razón de ser en que un estatuto proteccionista no cumpliría su finalidad si su aplicación dependiera de la mera voluntad de los ciudadanos. Este carácter adquiere mayor relevancia en aspectos como la contratación internacional y la celebración de contratos por medios electrónicos, como quiera que al tratarse de normas de orden público su aplicación no puede ser soslayada so pretexto de la libertad contractual que existe en las relaciones privadas internacionales. Nótese además que instrumentos internacionales como la Convención de Viena de 1980 dejan por fuera de su ámbito de aplicación las compraventas internacionales celebradas con consumidores.

30 VELILLA, Marco Antonio. Introducción al derecho de los negocios, p. 164, E1 Navegante editores, Ediciones jurídicas Gustavo Ibañez, Bogotá, 2001.

Bogotá, D.C. Colombia - Volumen XII - No. 24 - Julio - Diciembre 2009 - ISSN 0121-182X 


\subsubsection{Tiene fundamento constitucional}

El artículo 78 de la Constitución política estipula la necesidad de la regulación del control de calidad de bienes y servicios ofrecidos y prestados a la comunidad, así como la información que debe suministrarse al público en su comercialización. En igual forma se refiere a la responsabilidad de los productores y comercializadores que atenten contra la salud, seguridad y el adecuado aprovisionamiento a consumidores y usuarios. Este postulado ha tenido un desarrollo por parte de la Corte Constitucional. Al respecto esta alta corporación ha manifestado:

"La Constitución ordena la existencia de un campo de protección en favor del consumidor, inspirado en el propósito de restablecer su igualdad frente a los productores y distribuidores, dada la asimetría real en que se desenvuelve la persona que acude al mercado en pos de la satisfacción de sus necesidades humanas. Sin embargo, la Constitución no entra a determinar los supuestos específicos de protección, tema este que se desarrolla a través del ordenamiento jurídico. El programa de protección, principalmente, se determina a partir de la ley, los reglamentos y el contrato. Es claro que la fuente contractual debe interpretarse de conformidad con los principios tuitivos del consumidor plasmados en la Constitución. Con el derecho del consumidor se presenta algo similar de lo que se observa con otros derechos constitucionales. La Constitución delimita un campo de protección, pero el contenido preciso del programa de defensa del interés tutelado, es el que se desarrolla y adiciona por la ley y por otras normas y fuentes de reglas jurídicamente válidas. En particular, trazado el marco constitucional, a la ley se confía el cometido dinámico de precisar el contenido específico del respectivo derecho, concretando en el tiempo histórico y en las circunstancias reales el nivel de su protección constitucional. El significado de un determinado derecho y su extensión, por consiguiente, no se establece sólo por la Constitución a priori y de una vez para siempre" 31 .

La Corte constitucional justifica la protección al consumidor desde el siguiente punto de vista:

"La Constitución en relación con ciertas categorías de personas - menor, adolescente, anciano, mujer cabeza de familia, trabajador, indigente etc. - dispone un tratamiento de especial protección. En unos casos se persigue reforzar el respeto a la dignidad de la persona humana, sobre todo tratándose de personas que se encuentran en situación de debilidad manifiesta o que por su condición de extrema fragilidad pueden ser objeto de abusos por los demás. En otros casos, la Constitución aspira, con el régimen de especial protección, avanzar sostenidamente el ideario de igualdad sustancial inherente al Estado social de derecho. Con sus particularidades, la Constitución ha querido instaurar un régimen de protección en favor del consumidor y usuario de bienes y servicios que circulan en el mercado.

Como ya se ha expresado, la razón de ser de este régimen estriba en la necesidad de compensar con medidas de distinto orden la posición de inferioridad con que consumidores y usuarios, por lo general dispersos y dotados de escasos conocimientos y potencialidades, enfrentan a las fuerzas de la producción y comercialización de bienes y servicios, necesarios en orden a la satisfacción de sus necesidades materiales. Cuando la Constitución encomienda al legislador el desarrollo de un cierto régimen de protección, no está simplemente habilitando una competencia específica para dictar cualquier tipo de normas. Lo que el Constituyente se propone es que la finalidad de la protección efectivamente se intente actualizar y se imponga en la realidad política y social - por lo menos en un grado razonable y en la medida de las posibilidades y recursos existentes-, articulando de la manera más armoniosa y eficaz dentro de

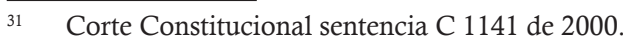


las políticas públicas las justas demandas de los sujetos merecedores de dicha protección especial" ${ }^{\prime 2}$.

Se observa entonces que el carácter proteccionista del derecho del consumo está plenamente justificado por esta Corte, así como la consideración de los consumidores como una categoría de sujetos dignos de protección, lo que descarta cualquier asomo de duda al respecto de la razón de ser y carácter de este derecho.

Por otro lado, los derechos de los consumidores pueden ser tutelados de manera individual o colectiva según la Constitución Política, que permite que a través de las acciones de grupo se pueda demandar la defensa de los intereses de los consumidores. Se evidencia así que los consumidores son una nueva categoría de individuos en el derecho moderno, tal y como son considerados los comerciantes o los trabajadores.

La consagración constitucional de la protección a los consumidores es un fenómeno generalizado y hoy en día en gran número de cartas fundamentales se propende por la protección de esta categoría de individuos, por ejemplo en la Constitución Argentina el artículo 42 dispone "Los consumidores y usuarios de bienes y servicios tienen derecho, en la relación de consumo, a la protección de la salud, seguridad e intereses económicos; a una información adecuada y veraz; a la libertad de elección y a condiciones de trato equitativo y digno". La Constitución federal brasileña de 1988 menciona la defensa al consumidor en el artículo $5^{\circ}$ como derecho fundamental y en el artículo 170 como principio ordenador del orden económico. ${ }^{33}$ La constitución peruana de 1993 en su artículo 65 expresa que "el Estado defiende los

32 Corte Constitucional sentencia C 973 de 2002.

33 LIMA MÁRQUEZ, Claudial. Los derechos del consumidor. Una visión comparativa entre el Brasil y la Argentina. intereses de los consumidores y usuarios". E1 artículo 51 de la Constitución española de 1978 establece que el Estado garantizará la defensa de los consumidores y usuarios y protegerá la seguridad, la salud y los legítimos intereses económicos de los mismos.

Se advierte en forma clara como el artículo 78 consagra los postulados fundamentales del derecho del consumo, el deber de información y el deber de seguridad que tienen los productores frente a los consumidores. Estos dos principios constituyen hoy en día la columna vertebral de la protección a los consumidores y se relacionan con los derechos que tradicionalmente se han reconocido a los consumidores, el derecho a ser informado, el derecho a la seguridad, el derecho a asociarse y el derecho a ser escuchado, tal y como se verá a continuación.

\subsubsection{Es un derecho con gran contenido social}

El derecho del consumo busca la protección de sujetos en situación de debilidad, los consumidores. Se trata de un nuevo derecho social, al igual que el derecho laboral se independizó del derecho civil para convertirse en un conjunto de normas que regulan las relaciones desiguales entre empleadores y trabajadores, el derecho del consumo tomó un rumbo propio en el ámbito del derecho privado y el derecho público. Según Mosset Iturraspe "La antigua y repetida frase cobra vigencia: consumidores somos todos. Vale decir que no se trata de un estatuto para un "cierto personaje": el tambero mediero o el encargado de casas de rentas, sino de un estatuto para alcanzar a todos los hombres que integran la sociedad civil; donde adquiere razón la comparación de este personaje central de los tiempos actuales, el consumidor, con otros personajes que, e otros tiempos, preocuparon al jurista de manera especial: hombres libres y esclavos, en el derecho Romano; ciudadanos, en la legislación que siguió a la Revolución 
Francesa; trabajadores, en los últimos años del siglo XIX y primeras décadas del siglo XX" ${ }^{34}$.

Señala Farina que el derecho del consumo entra en el terreno de los llamados intereses difusos, citando a Andorno, aquellos "intereses que no pertenecen a una persona aislada, ni a un grupo nítidamente delimitado de personas, sino a una serie indeterminada, cuyos miembros no están ligados necesariamente por vínculos jurídicos definidos"35. Señala además este autor: "Surge así la necesidad contemporánea de proteger dichos intereses difusos, superando la concepción clásica, tradicional, individualista, centrada fundamentalmente en la defensa de los intereses subjetivos e intereses legítimos de las personas, dándose paso una verdadera transformación del derecho, con una visión más solidaria y humana, que tienda a enaltecer las denominadas "calidades de vida" de la población ${ }^{36}$.

La protección de los derechos de los consumidores a través de acciones colectivas o populares contemplada en la constitución política reafirma la relevancia que socialmente tiene la debida tutela de los derechos de este grupo de ciudadanos grupalmente considerados. Las ligas y asociaciones de consumidores deben jugar un papel activo en el ejercicio de estas acciones...

\section{3. ÁMBITO DE APLICACIÓN}

El amplio espectro de las situaciones cubiertas por el derecho del consumo hace inútil enunciar los aspectos cobijados por el mismo, pues en todo tipo de situación o de relación jurídica en que se encuentren en juego intereses de los consumidores el derecho del consumo hace

\footnotetext{
34 MOSSET ITURRASPE, Jorge y LORENZETTI, Ricardo Luis. Defensa del Consumidor, p. 16, Rubinzal Culzoni Editores, Buenos Aires, 1993.

35 FARINA, Juan M. Op. cit. p. 322.

$36 \quad$ Ibid. p. 323.
}

presencia. Sin embargo vamos a enunciar y a explicar brevemente los pilares fundamentales del derecho del consumo alrededor de los cuales gira su campo de cobertura, a saber, los deberes de los productores y los derechos de los consumidores.

\subsection{Dos deberes básicos de los productores}

\subsubsection{El deber de información}

Este principio en Colombia tiene un carácter constitucional ya que el artículo 78 de la Constitución Política se refiere a la necesidad de regulación sobre la información que se da al público en la comercialización de bienes y servicios. El deber de información consiste básicamente en que el productor tiene la obligación de dar información veraz, suficiente y clara al consumidor acerca de las características, utilidad, forma de utilización, contraindicaciones, $\mathrm{y}$ en general sobre todo aquello que le permita al consumidor tomar una decisión consciente acerca de la necesidad de adquirir un bien o servicio que se le ofrece y le evite eventualmente un perjuicio al consumidor. Este deber se fundamenta en la asimetría informativa que existe en el mercado entre consumidores y productores, la cual puede ser neutralizada a través de la información que proporcionan los proveedores de bienes y servicios, con el objeto de efectuar: a) una adquisición informada y b) un uso adecuado, una vez practicado el acto de consumo $^{37}$.

El deber de información cobija aspectos como la publicidad engañosa, la veracidad de los contenidos de las etiquetas y embalajes de los productos, la indicación debida de precios al consumidor, el consentimiento informado, entre otras. El estatuto colombiano de protección al consumidor regula algunos de estos aspectos en lo referente a marcas, leyendas y

$37 \quad$ VEGA MERE. Op. cit. p. 96,97. 
propagandas (art. 14), propagandas con imágenes (art. 15), propagandas con incentivos (art. 16), precios máximos al público (art 18), regulación a la fijación de precios (Arts. 19-22).

Llevando estos aspectos al campo contractual tienen que ver con la formación del consentimiento en la celebración de un negocio jurídico, como quiera que la falta de veracidad o la omisión de la información no permitan al consumidor emitir una manifestación de voluntad libre y espontánea. En casos especiales se necesita que esa manifestación de voluntad sea además ilustrada, es decir, que el productor debe cerciorarse de informar debidamente al consumidor sobre algunos aspectos, alcanzando nuevos grados de formalismo, so pena de que el acto jurídico quede privado de eficacia. Un ejemplo de esto se da en materia de celebración de préstamos para la compra de vivienda en el ordenamiento jurídico francés que incluye obligaciones de información, tiempos de retracto o de reflexión y la obligación de menciones manuscritas.

\subsubsection{El deber de seguridad}

El productor debe velar porque los bienes o servicios que ingrese al mercado no atenten contra la salud e integridad de los consumidores, so pena de indemnizar los perjuicios que se le causen. En tal sentido los productores son responsables de la idoneidad y calidad de los bienes o servicios que ofrezcan (art. 23 estatuto del consumidor). Este punto ha sido tal vez aquel que mayor impacto ha generado en la sociedad, como quiera que algunos bienes o productos defectuosos han generado perjuicios irremediables en un sinnúmero de personas. E1 caso de la talidomida en Alemania es uno de ellos.

Se podría pensar que se trata de un aspecto jurídico que se regula por las reglas generales de la responsabilidad civil, pero el legislador ha optado por crear unas reglas especiales de responsabilidad para estos casos. Se habla de responsabilidad civil por productos defectuosos. El estatuto del consumidor colombiano se refiere específicamente a la garantía mínima presunta (art. 11 y 29), otras garantías (art. 12, 13 y 29), la solidaridad entre productor y vendedor en tratándose de bienes importados (art. 23), responsabilidad por información no veraz (art. 31), causales de exoneración de la responsabilidad (art. 26 y 27), fuerza mayor (art. 30), indemnización de perjuicios (art. 36, 37 y 40).

\subsection{Los derechos de los consumidores}

En el año 1962 el presidente Kennedy en su famoso discurso propuso cuatro derechos básicos de los consumidores que perduran, el derecho a la información, el derecho a la seguridad, el derecho a ser escuchado y el derecho a escoger. Sin embargo a raíz del desarrollo que el tema ha tenido a nivel mundial se han promovido otros derechos de los consumidores ${ }^{38}$.

- Derecho a ser informado.

- Derecho a la seguridad.

- Derecho a asociarse.

- Derecho a ser escuchado de manera individual y colectiva.

- Derecho a la reparación de daños y perjuicios.

- Derecho a un medio ambiente sano.

- Derecho a la revocación (o retracto)

- Derecho a la igualdad de trato (no discriminación)

- Derecho a la libre elección de bienes y servicios.

38 Una Directiva de la ONU de 1985 promueve los siguientes derechos de los consumidores: Protección frente a los riesgos de la salud y la seguridad; acceso a la información adecuada, posibilidades de educación efectiva entre consumidores; educación; libertad para formar grupos $\mathrm{u}$ organizaciones de consumidores. Tomado de Durand Carrion, op. Cit. P- 115, 116. 
- Derecho a la protección de sus intereses económicos.

- Derecho a la educación.

Alrededor de estos deberes y derechos se circunscribe el ámbito de aplicación del derecho del consumo, lo que de entrada permite afirmar que es bastante amplio y no es fácil de delimitar, pues en cualquier relación jurídica que estén en juego intereses de los consumidores se procurará la defensa de estos a través de sus normas especiales.

\subsection{El derecho del consumo y el derecho privado}

El derecho del consumo irrumpió con fuerza en el ámbito del derecho privado tradicional. En materia de relaciones contractuales el derecho del consumo aboga por la protección de la parte débil de la relación jurídica obligacional entre productor y consumidor, denominada relación de consumo, lo cual se ha traducido en normas de protección a la formación del consentimiento como el deber de información y el derecho de retracto, la interpretación contra proferentem, la interpretación favor debilis o pro consumidor, la regulación de contratos de adhesión con consumidores, la prohibición de cláusulas abusivas, la regulación de cláusulas de exoneración y limitación de la responsabilidad con consumidores, entre otras. Según Bianca: "La disciplina de contratos del consumidor ha cambiado el viejo cuadro normativo fundado sobre el axioma de la intangibilidad del acto de autonomía privada. Tal disciplina, en efecto, introduce el principio del control sustancial del contrato como regla de tutela que tutela al contratante, no en razón de sus condiciones o calidades particulares, sino en razón de su sujeción al poder de reglamentación del contrato que detentan los productores y distribuidores de bienes y servicios" ${ }^{\prime 3}$. La categoría de los

39 BIANCA C., Mássimo. Derecho Civil, el contrato, Universidad Externado. contratos de consumo ha adquirido tal relevancia que para autores como Lorenzetti hoy en día es más importante hacer la distinción entre contratos de consumo y contratos entre empresas, que mantener la antigua distinción entre contratos civiles y comerciales ${ }^{40}$.

Sin embargo debe advertirse que la relación de consumo no es de naturaleza exclusivamente contractual, para la doctrina argentina la relación de consumo cobija vínculos jurídicos extracontractuales. La relación de consumo es más amplia que la noción de contrato, que sólo incluye al consumidor individual, mientras la primera cobija al consumidor o usurario individual o colectivamente considerados ${ }^{41}$. Según Lorenzetti "La relación de consumo no toma como base al acto de contratar sino al acto de consumir, que es un hecho jurídico" ${ }^{42}$, además los hechos ilícitos pueden dar lugar a una relación de consumo, lo cual reafirma el hecho de que "en el derecho del consumidor se tiende a la supresión del distingo entre responsabilidad contractual y extracontractual" 43 . En este orden de ideas, se puede afirmar que la relación de consumo es un vínculo jurídico obligacional de carácter especial propio de las relaciones económicas capitalistas de la vida moderna, que se puede configurar en la fases precontractual, contractual o extracontractual, y que además rompe con los esquemas tradicionales del derecho privado, por lo cual debe ser objeto de un análisis en capítulo aparte de esta investigación.

En el derecho colombiano algunos de estos aspectos del derecho del consumo todavía

40 LORENZETTI, Ricardo Luis. Tratado de los Contratos, parte general, p. 81, Ribinzal Culzoni editores, Buenos Aires, 2004.

41 LORENZETTI, Ricardo Luis. Tratado de los contratos, Tomo I, p. 147, Rubinzal Culzoni Editores, Buenos Aires, 2007.

42 Ibid.. p. 149.

$43 \quad$ Ibid. p. 147. 
tienen una regulación precaria e insuficiente, contrario a lo que sucede en algunos ordenamientos jurídicos como el comunitario europeo en el cual se ha llevado el tema de la protección al consumidor, influenciado por una perspectiva social, a un grado de desarrollo bastante alto. En Colombia, por ejemplo en materia de contratos de adhesión una sola norma en regula este aspecto, el artículo 1624 del Código Civil ${ }^{44}$. Así mismo, en lo atinente a cláusulas abusivas no existe ningún tipo de regulación y la jurisprudencia al respecto es casi inexistente. Todo lo anterior hace pensar que la legislación colombiana está rezagada en la regulación de estos temas, pues no siempre los principios generales del derecho privado son suficientes para solucionar problemas que hace cien años eran insospechados.

\section{CONCLUSIONES}

El derecho del consumo es de reciente aparición y responde a las necesidades de las situaciones de mercado del mundo actual. En algunos ordenamientos jurídicos, sobre todo en economías de países desarrollados ha tenido un desarrollo importante, mientras en otros como el colombiano ha tenido un desarrollo lento y los avances que se presentan son demasiado tímidos.

El estatuto de protección al consumidor colombiano data de 1982 y a pesar de que regula aspectos como el deber de información y el deber de seguridad de los productores, esta norma merece ser remozada para ponerse a tono con aspectos cruciales del derecho

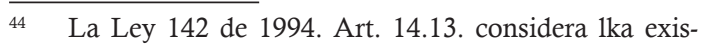
tencia de una posición de dominio contractual entre la empresa prestadora del servicio y el usuario. Art. 14.13. Posición dominante. Es la que tiene una empresa de servicios públicos respecto a sus usuarios; y la que tiene una empresa, respecto al mercado de sus servicios y de los sustitutos próximos de éste, cuando sirve al $25 \%$ o más de los usuarios que conforman el mercado. moderno. En tiempos en que se predica la inserción del país en la economía internacional y la integración económica en sus diferentes niveles ya sea a través de tratados de libre comercio o la inserción en bloques económicos (uniones aduaneras o mercados comunes), el país debe contar con un ordenamiento jurídico que le permita ingresar de manera adecuada a estos contextos, sobre todo protegiendo a sus ciudadanos en situaciones de mercado que se vuelven cada día más complejas. Es en este momento que la legislación se debe revisar para que sea idónea en temas como la protección al consumidor, el derecho de la competencia, las normas de propiedad intelectual, entre otros.

El derecho del consumo encuentra su razón de ser en la necesidad de proteger relaciones jurídicas que en algunas situaciones son asimétricas, como la relación consumidor - productor. Es un derecho de carácter tuitivo que ha tenido plena aceptación en diferentes ordenamientos jurídicos para proteger a una nueva categoría de ciudadanos, los consumidores. Así como existe un derecho del trabajo para los trabajadores existe un derecho del consumo para los consumidores.

El derecho del consumo tiene una fisonomía propia, que lo distingue de otras ramas o perspectivas del derecho, y su grado de importancia se revela en que en la protección a los consumidores es un imperativo de orden constitucional en muchos ordenamientos jurídicos. A través de diferentes medios la protección al consumidor es una realidad en muchos Estados y en niveles de integración económica es indispensable contar con normas que respondan a las necesidades de mercados comunes.

El derecho del consumo se inmiscuye en diferentes áreas del derecho, no es derecho público ni privado. Sin embargo, se puede evidenciar más proximidad con el derecho privado, como quiera que las relaciones jurídicas que se consideran de consumo se configuran en su gran 
mayoría entre personas naturales o jurídicas de naturaleza privada.

En el área del derecho privado rompe con esquemas y postulados del derecho clásico contenido en códigos decimonónicos. Implica una restricción al principio de la autonomía de la voluntad porque el legislador interviene en las relaciones jurídicas de los particulares, en las relaciones de consumo, imponiendo ciertas obligaciones frente al consumidor, tales como el deber de información, la protección contra cláusulas abusivas, y en algunos casos estableciendo un derecho de retracto a favor del consumidor a pesar de que el negocio jurídico se encuentre perfeccionado. Conlleva igualmente un replanteamiento del derecho contractual porque cuando existe una relación de consumo varían algunas normas aplicables al negocio jurídico.

Los principios del derecho del consumo, los deberes de los productores, los derechos de los consumidores, así como los aspectos contractuales del derecho del consumo, son bastante amplios y en algunas ocasiones complejos, por lo cual merecen un tratamiento aparte, más juicioso. En este artículo, a manera de introducción al derecho del consumo, tan sólo se pretendió hacer mención de ellos con la finalidad de esbozar los alcances de este nuevo derecho.

La poca importancia que tiene esta materia en Colombia puede encontrar dos explicaciones, en primer lugar una no jurídica, de orden social, consistente en que no existe una cultura del consumo, del consumo responsable, sino más bien del consumismo, es decir de consumir por consumir; lo que a su vez ha conllevado a cierto conformismo del consumidor, que no reclama, no conoce sus derechos, ni le interesan, no denuncia. El ciudadano no se comporta como consumidor y no hace valer sus derechos. La explicación jurídica a este problema consiste en que la normatividad colombiana no ha promovido ni facilitado la creación de una cultura del consumo responsable, no ha creado una consciencia de consumidor en el ciudadano, ni le ha brindado los medios a los ciudadanos para que defiendan sus derechos. E1 consumidor necesita medios expeditos para hacer valer sus derechos, ante el exceso de trámites burocráticos y la ineficiencia de las autoridades un consumidor no se sentirá estimulado a reclamar la protección de sus derechos. Debe considerarse que el derecho del consumo es un derecho de pequeñas causas en la mayoría de los casos y la legislación debe responder a esta realidad ofreciendo medio mecanismos idóneos de protección. En todo caso en Colombia algo está fallando frente al tema de la protección al consumidor y se considera que la legislación y las autoridades tienen un grado de responsabilidad al respecto.

\section{BIBLIOGRAFÍA}

ALPA, Guido. El derecho de los consumidores y el "Código del Consumo" en la experiencia italiana, Revista de derecho privado No. II-2006, Universidad Externado de Colombia.

BIANCA C., Mássimo. Derecho Civil, el contrato, Universidad Externado, Bogotá, 2005.

CALAIS-AULOY, Jean. Droit de la Consommation, 7e édition, Dalloz, Paris, 2006.

DURAND CARRION, Julio. Tratado de derecho del consumidor en el Perú, Universidad San Martin de Porres, $1^{\text {a }}$ edición, Lima, 2007.

FARINA, Juan M. Contratos comerciales modernos, Editorial Astrea, Buenos Aires, 2005.

GONZÁLEZ VAQUÉ, Luis. Las nociones de consumidor medio y miembro de un grupo particular de consumidores en el Reglamento No. 1924/2006, en gaceta jurídica de la unión europea y de la competencia, No. 247, 9-19. (2007).

GHERSI, Carlos Alberto. Contratos civiles y Comerciales, Tomo I, $5^{\text {a }}$ edición, Editorial Astrea, Buenos Aires, 2002. 
LORENZETTI, Ricardo Luis. Tratado de los Contratos, parte general, Rubinzal Culzoni editores, Buenos Aires, 2004.

LORENZETTI, Ricardo Luis. Tratado de los contratos, Tomo I, Rubinzal Culzoni Editores, Buenos Aires, 2007.

MÁRQUEZ ROBLEDO, Felipe. Apuntes de derechoeconómicoy dela competencia, segunda edición, Universidad Javeriana, Bogotá, 2007.

MOSSET ITURRASPE, Jorge y LORENZETTI, Ricardo Luis. Defensa del Consumidor, Rubinzal-Culzoni Editores, Buenos Aires, 1993.

NIHOUL, Paul. Introducción al Derecho de la competencia, Universidad Externado de Colombia, Bogotá, 2005.

OVALLE FAVELA, Jorge. Los derechos del consumidor, Cámara de Diputados, Universidad Nacional Autónoma de México.

PÉREZ BUSTAMANTE, Laura. Derechos del Consumidor, Editorial Astrea, Buenos Aires, 2004.
POILLOT, Elise. Droit Europeén de la consommation et uniformisation du droit des contrats. LGDJ, Paris 2006.

RIVEROS SÁNCHEZ, Juan Marco. Quo Vadis Derecho del Consumidor, Biblioteca jurídica Dike, Medellín, 1997.

RUBIO ESCOBAR, Jairo. Derecho de los mercados, Legis, Bogotá, 2007.

TAORMINA, Gilles. Théorie et pratique du droit de la consommation, Editeur Librairie de l'université d'Aix en Provence, 2004.

VELILLA, Marco Antonio. Introducción al derecho de los negocios, El Navegante editores, Ediciones jurídicas Gustavo Ibañez, Bogotá, 2001.

VEGA MERE, Yuri. Contratos de Consumo, Editorial Grijley, Lima, 2001.

WEINGARTEN Celia. Derecho del Consumidor, Editorial Universidad, Buenos Aires, 2007. 